\title{
Characterization of Dissolved Organic Matter in River Water by Conventional Methods and Direct Sample Analysis-Time of Flight-Mass Spectrometry
}

\author{
T. Garrido Reyes and J. Mendoza Crisosto \\ Departamento de Química Inorgánica y Analítica, Facultad de Ciencias Químicas y Farmacéuticas, \\ Universidad de Chile, Sergio Livingstone 1007, Independencia, Casilla 233, 8380492 Santiago, Chile
}

Correspondence should be addressed to T. Garrido Reyes; tgarrido@ciq.uchile.cl

Received 16 March 2016; Revised 16 May 2016; Accepted 24 May 2016

Academic Editor: Athanasios Katsoyiannis

Copyright (C) 2016 T. G. Reyes and J. M. Crisosto. This is an open access article distributed under the Creative Commons Attribution License, which permits unrestricted use, distribution, and reproduction in any medium, provided the original work is properly cited.

\begin{abstract}
The dissolved organic matter in surface waters is composed of fractions of different molecular weight and polarity, characteristics that determine their capacity for complexing different types of pollutants and their environmental impact. In this study, the dissolved organic matter in the surface water of the Bio-Bio River (Central Region of Chile) was characterized chemically and spectroscopically after fractionating by molecular weight and polarity. The technique of direct sample analysis-time of flight-mass spectrometry (DSA-TOF-MS) was used to obtain more information on the composition of dissolved organic matter. It is concluded that dissolved organic matter found in the water of the river from the site of minor human impact (Rucalhue) has a predominantly natural origin, with a high content of aromatic carbon, in contrast to dissolved organic matter found in the waters of the sites that have higher human impact (Laja and Concepción), characterized by a greater molecular size and higher organic carbon content. These results are consistent with those obtained from DSA-TOF-MS, where higher correlation was observed between the mass spectrum of the standard commercial humic acid and dissolved organic matter found in the sectors of Laja and Concepción, unlike the spectrum mass of lignin which is more like dissolved organic matter found in the sector Rucalhue.
\end{abstract}

\section{Introduction}

Organic matter is a complex and varied mixture of aromatic and aliphatic hydrocarbons with functional groups such as amides, carboxyl, hydroxyl, and ketones and others in smaller amounts [1-3]. This organic matter may come from natural sources like the soil or from anthropic sources like organic amendments (compost or biosolids) or spillage from sanitary landfills. Two kinds of organic matter can be identified, usually more abundant, which under normal soil conditions are insoluble and another pool of dissolved organic matter (DOM). The latter can migrate to water from different kinds of sources, either natural or anthropic, such as that added to the ecosystem by spillage from sanitary landfills or through the addition of compost or biosolids to the soil (agricultural land, forests, and pastures) [4].

The substances that compose the DOM have the ability to retain and/or mobilize organic and inorganic pollutants in the environment $[1,5,6]$, and it is the kind and nature of the existing functional groups present, like carboxyl $(-\mathrm{COOH})$, phenol (benzene- $\mathrm{OH})$, alcohol $\left(-\mathrm{CH}_{2}-\mathrm{OH}\right)$, and methoxyl $\left(-\mathrm{OCH}_{3}\right)$, that can influence its interaction ability with the different pollutants $[7,8]$.

The variety of molecules that constitute the DOM and their low concentration in water systems make their characterization complex $[4,9]$. Therefore, to facilitate their study it is often necessary to isolate and concentrate them by methods such as reverse osmosis, evaporation under reduced pressure, or freeze-drying $[2,4,10]$ and then fractionate them according to their polarity using fractionating resins like Amberlite XAD or by molecular size through techniques like ultrafiltration, ultracentrifugation, and high performance size exclusion chromatography $[6,11,12]$. When analyzed by $\mathrm{H}^{1}$-NMR, FTIR, fluorescence, UV-Vis, and GC-MS techniques, these fractions provide information related to the components of the DOM, and they are used as its fingerprints 
$[6,13,14]$, characteristics that allow predicting its behavior in the environment and its effect on a variety of pollutants [15].

In recent years research work related with DOM has increased considerably, because of its effect of retention or transport of organic and inorganic pollutants in different natural substrates $[5,16,17]$.

In Chile there are several studies aimed at the characterization of basins of great significance to agriculture, such as the Traiguén River [18], the Cachapoal and Coya Rivers in the VI Region [19], and the Laja River in the VIII Region [20]. Such studies have been conducted with the objective of determining the levels of various pollutants in order to assess the possible effects on the soil and the products generated by this activity $[18,21]$. However, there is little information about the DOM in the rivers of Chile, even though their characterization is of great importance because it can modify the fate of the pollutants present in the water.

The Bio-Bio basin is part of the VIII Region and it is one of the country's largest basins $\left(24,264 \mathrm{~km}^{2}\right)$ and water flows, covering part of the Provinces of Malleco and Cautín in the IX Region. At the national level the basin represents an important economic development center, linked to the forestry sector, livestock sector (located mainly in the provinces of Nuble and Bio-Bio), the industrial sector (represented basically by the metallurgical and chemical industries, oil refineries, the textile industry, and the cellulose industries, among others), and the hydroelectric sector, which is the main source of electric power at the national level. All this confirms the importance of evaluating the presence of DOM and its physicochemical characteristics, as well as the effect that it can have on the pollutants present in the Bio-Bio River.

Because of the complexity of the DOM, in a first stage it is necessary to extract it and then fractionate it either according to molecular weight by means of ultrafiltration or according to polarity by the method described by Leenheer [22]. Then the structural characterization of each fraction is made by techniques like elemental analysis, FTIR and UV-Vis analysis, and $\mathrm{H}^{1}$-NMR spectrometry.

Currently there is a lack of a standard analytical methodology for the structural characterization of the DOM, and this can be described only partially from various analyzes. In recent decades, new techniques have been used for the characterization of DOM, such as Fourier Transform Ion Cyclotron Resonance Mass Spectrometry [3], Electrospray Ionization Fourier Transform Ion Cyclotron Resonance Mass Spectrometry [23], and Matrix Assisted Laser Desorption Ionization Time-of-Flight [24, 25].

Direct sample analysis-time of flight-mass spectrometry (DSA-TOF-MS) has proven to be a useful technique in the analysis of natural DOM, with advantages such as speed of analysis, fast screening of samples in seconds, without sample preparation [26]. Direct sample analysis (DSA) is an open atmosphere ambient ionization technique which utilizes power of field-free atmospheric pressure chemical ionization (APCI) source for rapid and direct analysis of samples (solid, liquid, or gas). In relation to DSA ionization mechanism, the heated nitrogen gas volatilizes the analytes present in the sample and hydronium ions donate protons to the analyte forming the ion $[\mathrm{M}+\mathrm{H}]^{+}$. The use of TOF-MS also allows greater resolution mass spectrometer with greater accuracy of the measured mass.

In soils and sediments we can identify organic matter of different sizes; within this, carbonaceous geosorbents (CG) can be identified, corresponding to organic material in the 63-500 $\mu \mathrm{m}$ diameter range, with high hydrophobicity; this property allows CG to intervene in the processes of sorption of different organic compounds such as terpenes [27] or contaminants such as polycyclic aromatics hydrocarbons (PAHs) [28]. The origin of the CG is varied; it may be of an anthropic origin, such as those by-products of the combustion of hydrocarbons, or natural, such as pollen or fungi spores; it is possible that part of this material can be transferred to rivers or lakes but due to their size, it becomes part of the sediment of these ecosystems [29]. The DOM, operationally defined as less than $0.45 \mu \mathrm{m}$, resembles CG in relation to interaction with organic pollutants. It has been reported that $\mathrm{CG}$, due to the long hydrological residence, can become transformed by natural geochemical processes, contributing to the DOM [30].

The purpose of this paper was to isolate and fractionate the DOM and then compare the structural and chemical characteristics of the isolated fractions of DOM from the same source, but from different sectors of the basin that differ in their anthropic activity. The study involves the use of DSA-TOF-MS technique, which has not been described in the characterization of DOM, hoping to provide new information on the characteristics of DOM from different sources. Such knowledge can assist in our understanding of the composition and chemical properties of DOM samples in aqueous environments.

\section{Materials and Methods}

2.1. Studied Area. The Bio-Bio River receives industrial and household discharges, and its course was followed from its source to its mouth in the Pacific Ocean, considering three sampling zones that differ in their associated anthropic impact. The first sampling point was the Rucalhue sector, an area with a low water volume characterized by low anthropic impact. The second sampling point was in Laja, between Nacimiento and San Rosendo, with a river width of approximately $2 \mathrm{~km}$, and the samples were taken from a boat; this sector receives wastes from the nearby cellulose plants. The third sampling point was in Concepción, a zone with a large water volume and a high anthropic impact (Figure 1).

2.2. Water Sample Collection and Characterization. The samples were collected every $10 \mathrm{~min}$ in high-density polyethylene bottles that had been decontaminated with $10 \% \mathrm{HNO}_{3}$, completing a total of ten samples with a volume of approximately $2.5 \mathrm{~L}$ each. The samples were transported to the laboratory and were stored at $4^{\circ} \mathrm{C}$ for their immediate analysis, with a part of them being frozen for later use.

The $\mathrm{pH}$, conductivity, organic carbon content, and suspended solids of the samples were determined. The method of Walkley-Black modified for water was used to determine 


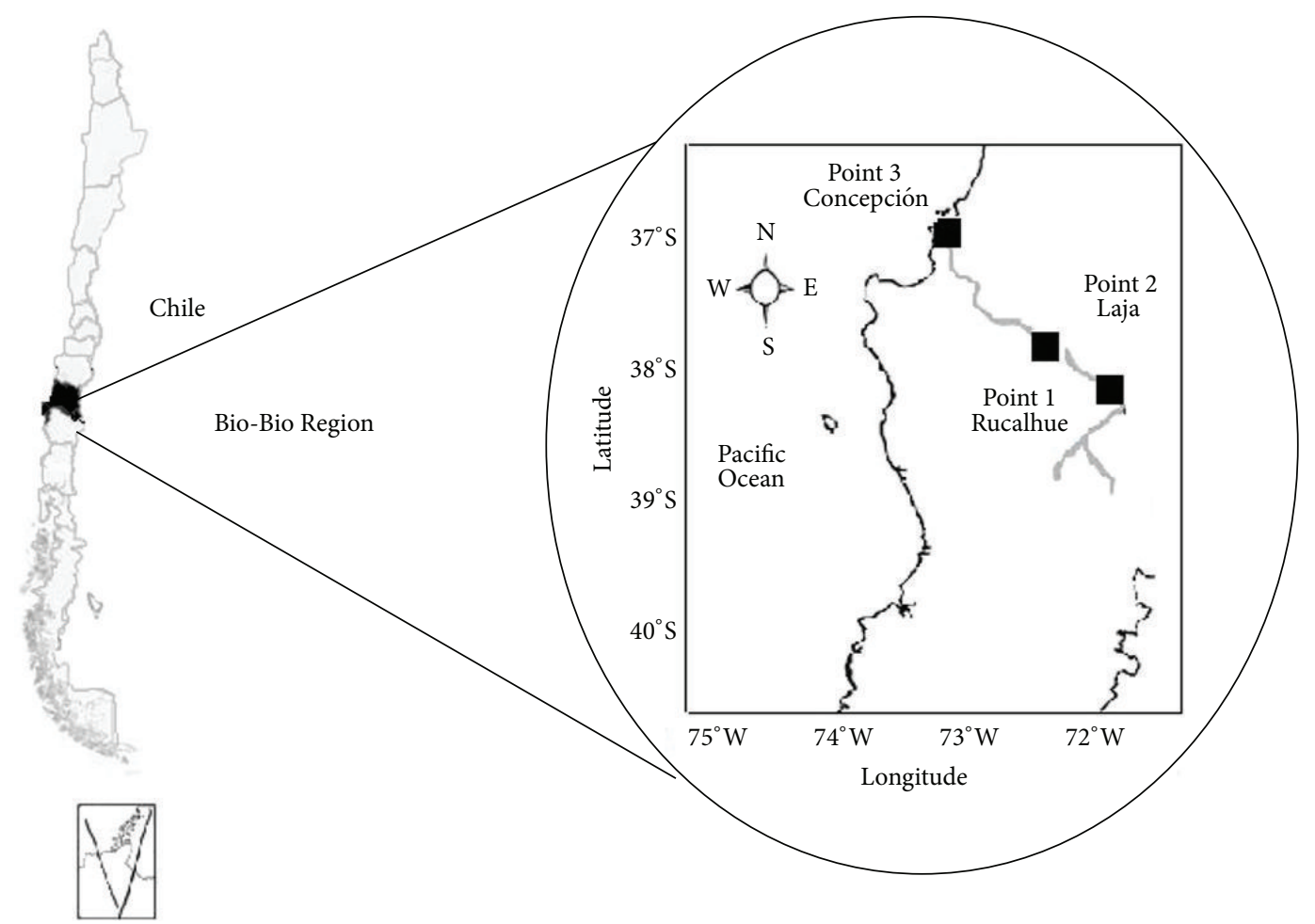

FIGURE 1: Geographical location of water sampling points from Bio-Bio Rivers, VIII Region, Chile.

organic carbon in the water samples, prior correlation of the data with the quantification of total organic carbon (TOC) determined with a Vario TOC Select analyzer (Elementar). Reproducible TOC values with an accuracy of $\pm 1 \%$ were always found by injecting $500 \mu \mathrm{L}$ aliquots in the analyzer. Suspended solids were determined by the ASTM method [31].

2.3. Characterization of the DOM. An initial volume of $2 \mathrm{~L}$ of sample was used, and it was concentrated in a rotavapor down to a volume of $50 \mathrm{~mL}$, followed by drying in a vacuum oven (WTB Winder), getting a representative solid that was studied by FTIR, $\mathrm{H}^{1}$-NMR, and elemental analysis.

2.4. Collection and Fractionation of DOM. The water samples were filtered through paper (Advantec, $70 \mathrm{~mm}$, number 2) and then the DOM was separated by filtration through a $0.45 \mu \mathrm{m}$ cellulose nitrate membrane (Sartorius Stedim Biotech), and this fraction was called DOM.

For the fractionation by molecular weight $4.0 \mathrm{~L}$ of DOM solution and a continuous ultrafiltration cell (Amicon, Millipore) were used, using an ultrafiltration membrane with $1 \mathrm{kDa}$ cutoff. The fractions greater than $1 \mathrm{kDa}(\mathrm{F} 1)$ and lower than $1 \mathrm{kDa}(\mathrm{F} 2)$ were concentrated to a volume of $200 \mathrm{~mL}$ in a rotavapor, and this volume was then divided into two fractions: one $150 \mathrm{~mL}$ fraction was dried in a vacuum drying oven (WTB Winder) and the remaining $50 \mathrm{~mL}$ was treated with sodium azide at a concentration of $100 \mathrm{mg} \cdot \mathrm{L}^{-1}(100 \mu \mathrm{L}$ of sodium azide in $50 \mathrm{~mL}$ of solution) to avoid the degradation of the DOM by microorganisms, and it was stored at $4^{\circ} \mathrm{C}$ for its later analysis. The dry residue obtained, representative of the DOM fractions, was studied by FTIR and by the organic carbon analysis described in Section 2.2 (Figure 2).

2.5. Fractionation of the DOM by Polarity. For the fractionation of the DOM according to polarity, use was made of the analytical procedure described by Leenheer [22], which consists of a separation of organic solutes in three fractions operationally defined as hydrophobic base (F3), hydrophobic acid (F4), and hydrophilic fraction (F5). This separation was done according to their adsorption by the ion exchange resin XAD-8 (Supelite, Supelco) (Figure 2).

The procedure was applied in triplicate to the F1 and F2 DOM fractions from each of the sampling points (Rucalhue, Concepción, and Laja), generating 18 fractions in total. In each of these fractions, the organic carbon content was determined in duplicate as described in Section 2.2.

2.6. Analysis of the DOM and Its Fractions by UV-Vis Spectroscopy. A solution with a carbon concentration of $10 \mathrm{mg} \cdot \mathrm{L}^{-1}$ was prepared at $\mathrm{pH} 6.5\left(10^{-3} \mathrm{~mol} \cdot \mathrm{L}^{-1}\right.$ phosphate buffer) with each of the DOM fractions obtained, and their absorbance was then determined by UV-VIS spectroscopy (UV/Vis spectrometer UV2, Unicam) at wavelengths of 204, 254, 250, 365, and $436 \mathrm{~nm}$. The specific UV-absorbance (SUVA) for each sample was determined as the quotient between the absorbance at $254 \mathrm{~nm}$ and the DOC concentration in the sample [32].

2.7. Analysis of the DOM and Its Fractions by DSA-TOF-MS. DOM representative of each sampling point and its fractions 


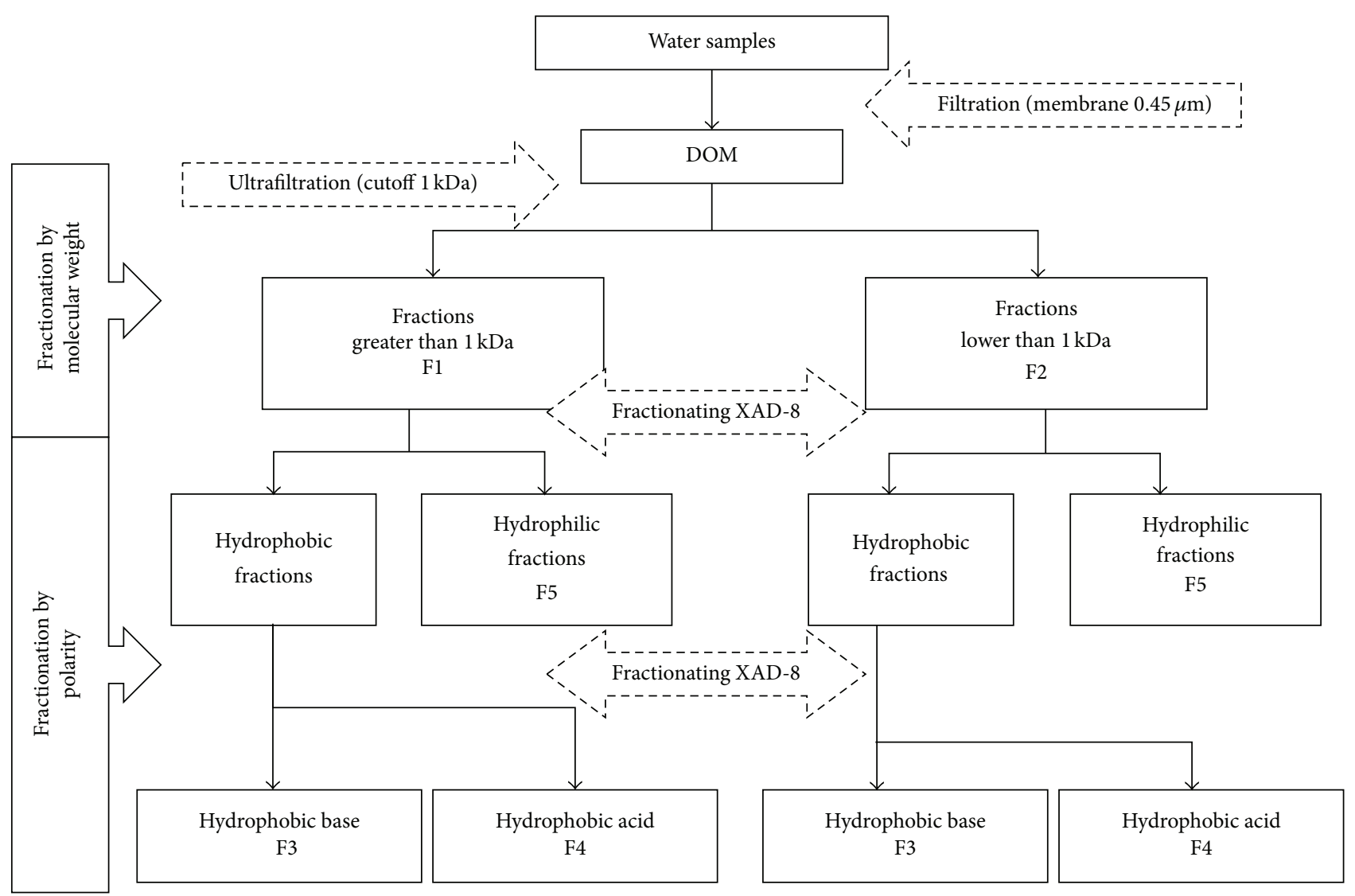

FIGURE 2: DOM fractionation scheme by molecular weight and polarity.

was used for this experiment. A solution of $5 \mathrm{mg} \cdot \mathrm{mL}^{-1}$ of DOM in HPLC grade water containing $0.1 \mathrm{~mol} \cdot \mathrm{L}^{-1} \mathrm{NaOH}$ was prepared. Furthermore, standard solutions of commercial humic acid (HA) and alkali lignin (LG) at the same concentration were considered, both standards supplied by Sigma Aldrich. The liquid sample $(10 \mu \mathrm{L})$ was placed in a mesh holder for analysis.

The AxION ${ }^{\mathrm{TM}}$ direct sample analysis-time of flight-mass spectrometry (AxION ${ }^{\mathrm{TM}}$-DSA-TOF-MS, Perkin Elmer) conditions were as follows: corona current of $30 \mu \mathrm{A}$, heater temperature of $300^{\circ} \mathrm{C}$, auxiliary gas $\left(\mathrm{N}_{2}\right)$ flow of $4 \mathrm{~L} \cdot \mathrm{min}^{-1}$, nebulizer gas $\left(\mathrm{N}_{2}\right)$ pressure of $552 \mathrm{kPa}$, drying gas $\left(\mathrm{N}_{2}\right)$ flow of $3 \mathrm{~L} \cdot \mathrm{min}^{-1}$, and drying gas $\left(\mathrm{N}_{2}\right)$ temperature of $25^{\circ} \mathrm{C}$. The AxION-DSA-TOF-MS was run in positive ionization mode with a flight tube voltage of $-10000 \mathrm{~V}$. The capillary exit voltage was set to $100 \mathrm{~V}$ for normal MS analysis and $155 \mathrm{~V}$ for collision induced dissociation analysis. Mass spectra were acquired with a mass range of $100-3000 \mathrm{~m} / z$ and an acquisition rate of one spectrum per second. All samples were analyzed for $10 \mathrm{sec}$. To maintain mass accuracy, five lock mass ions were used $(\mathrm{m} / \mathrm{z}$ 121.0509, $\mathrm{m} / z$ 622.0299, $\mathrm{m} / z$ 922.0119, $\mathrm{m} / \mathrm{z}$ 1521.9771, and $m / z$ 2121.9405).

\section{Results and Discussion}

3.1. Characterization of the Water. The amount and composition of DOM vary spatially and in time, not only for the surrounding environment, but also by environmental processes to which it is subjected. The main phenomena affecting the DOM are biodegradation and photodegradation, which at the end of the process would convert inorganic species, for example, $\mathrm{CO}_{2}$ [33]; this implies that one of the determinant factors for studying the DOM is the time of analysis, which must be controlled to minimize variability in the amount and composition of the DOM; for this reason we opted to collect 10 samples per sampling point. This allowed the analysis of samples in parallel, not avoiding degradation of the DOM, but if obtaining DOM under similar conditions for the three sampling points. While the information published recommends applying chemicals such as biocides or work at low temperatures to avoid degradation of the DOM, we check in the laboratory that these methods were not effective.

The organic carbon content (Table 1) of sampling point 3 was greater by one unit than that of points 1 and 2, whose values were 2.4 and $2.9 \mathrm{mg} \cdot \mathrm{L}^{-1}$, respectively. The conductivity was $89.4,114$, and $125 \mu \mathrm{S} \cdot \mathrm{cm}^{-1}$ for points 1,2 , and 3 , respectively. The results of the determination of the $\mathrm{pH}$ of the water were similar, with an average of 7.6 for the three sampling points. With respect to suspended solids, sampling points 1 and 2 had similar values of $12.9 \mathrm{~g} \cdot \mathrm{L}^{-1}$, in contrast with sampling point 3 , whose value was almost three units lower, in agreement with the flow volume differences between the sampling points, with the flow at point 3 greater than that at the other points. 
TABLE 1: Characterization of surface waters of the Bio-Bio River, VIII Region, Chile.

\begin{tabular}{lccc}
\hline Point & 1 & 2 & 3 \\
\hline Sector & Rucalhue & Laja & Concepción \\
Elevation $(\mathrm{m})$ & 846 & 139 & 144 \\
Coordinates & $37^{\circ} 43^{\prime} 16.9^{\prime \prime} \mathrm{S}$ & $37^{\circ} 17^{\prime} 02.5^{\prime \prime} \mathrm{S}$ & $36^{\circ} 49^{\prime} 37.9^{\prime \prime} \mathrm{S}$ \\
& $72^{\circ} 14^{\prime} 39.7^{\prime \prime} \mathrm{W}$ & $72^{\circ} 42^{\prime} 59.9^{\prime \prime} \mathrm{W}$ & $73^{\circ} 04^{\prime} 17.8^{\prime \prime} \mathrm{W}$ \\
$\mathrm{C}_{\text {org }}\left(\mathrm{mg} \cdot \mathrm{L}^{-1}\right)^{\mathrm{a}}$ & $2.38 \pm 0.07^{\mathrm{b}}$ & $2.88 \pm 0.01$ & $4.30 \pm 0.71$ \\
Conductivity $\left(\mu \mathrm{S} \cdot \mathrm{cm}^{-1}\right)$ & $89.4\left(20.6^{\circ} \mathrm{C}\right)$ & $114.2\left(20.5^{\circ} \mathrm{C}\right)$ & $7.5 .4\left(20.5^{\circ} \mathrm{C}\right)$ \\
$\mathrm{pH}$ & 7.63 & 7.55 & 7.56 \\
Suspended solids $\left(\mathrm{g} \cdot \mathrm{L}^{-1}\right)$ & $12.87 \pm 0.19$ & $12.88 \pm 0.46$ & $9.97 \pm 0.33$ \\
\hline
\end{tabular}

${ }^{a} \mathrm{C}_{\text {org }}$ : organic carbon content; ${ }^{\mathrm{b}}$ standard deviation.

DOM concentrations measured as organic carbon are reported as $1-10 \mathrm{mg} \cdot \mathrm{L}^{-1}$ in rivers, $1-50 \mathrm{mg} \cdot \mathrm{L}^{-1}$ in lakes, $8.6 \mathrm{mg} \cdot \mathrm{L}^{-1}$ in wastewater, and $0.5-52 \mathrm{mg} \cdot \mathrm{L}^{-1}$ in soil [34]. This organic matter can interact with the different pollutants present in the soil, and in the specific case of heavy metals, the organic matter can favor their stabilization in the soil solution [35], while in the specific case of DOM from residues such as compost, it can mobilize heavy metals through the soil profile [36].

3.2. Characterization of the DOM. One of the main problems of the study of DOM is the variability in the amount and composition of the material obtained. Therefore, analyzes were performed continuously, verifying the content of organic carbon in the subfractions obtained in each stage, to ensure the presence of DOM throughout the fractionation process by either polarity or molecular weight; such procedures were performed in triplicate, with relative standard deviation (RSD) of organic carbon content lower than $15 \%$. In this sense the DSA-TOF-MS technique is a great alternative, because for each fraction of DOM it is possible to obtain a highly reproducible mass profile, in short analysis times; however, as these profiles are highly complex it is impossible to associate a numerical variability with these results.

With respect to the determination of SUVA, the RSD of the determination of organic carbon and absorbance determined in the DOM were lower than $10 \%$; however, the values are not shown since the results of SUVA and relationships absorbance correspond to determinations obtained as quotients between the individual parameters.

The mass of DOM from river water at sampling points 1, 2 , and 3 was $70.7,63.4$, and $56.4 \mathrm{mg} \cdot \mathrm{L}^{-1}$, respectively. With respect to elemental microanalysis of the solid fraction of the DOM, the percentages for sampling point 1 were $\mathrm{N}: 0.1, \mathrm{C}: 4.9$, and $\mathrm{H}: 1.02$; for sampling point 2, N: 0.5 , C: 4.6, and $\mathrm{H}: 1.04$; and for sampling point 3, N: 0.7, C: 5.3, and H: 1.00 .

Because of the complexity of the structure of the DOM, the $\mathrm{H}^{1}$-NMR spectra were considered as a pattern of signals rather than as a means of identifying specific compounds (Supplementary Figure 1 in Supplementary Material available online at http://dx.doi.org/10.1155/2016/1537370). It must be noted that the distribution found resembles the spectra reported by [37], for fulvic acid, and that corresponding to the hydrophilic fraction with a signal at $0-4 \mathrm{ppm}$ for the aliphatic region and 6-8.6 ppm for the aromatic region.

The results of the FTIR analyses of the DOM are presented in Supplementary Figure 2 for the three sampling points, showing agreement between the spectroscopic profiles of the different DOM, indicating that the structures and functional groups are similar. The main signals are seen at $3422.3 \mathrm{~cm}^{-1}$, corresponding to the $\mathrm{H}$-bonded $\mathrm{OH}$ stretching of carboxyl, phenol, and alcohol; a lower intensity signal at $1637 \mathrm{~cm}^{-1}$ is corresponding to the $\mathrm{C}=\mathrm{O}$ stretching of $\mathrm{COO}^{-}$, ketonic $\mathrm{C}=\mathrm{O}$, and aromatic $\mathrm{C}=\mathrm{C}$ conjugated with the $\mathrm{COO}^{-}$of pyridine to amino acid; a signal at $1425,1 \mathrm{~cm}^{-1}$ is corresponding to -C-H of carbohydrates; and a strong signal at $1096.6 \mathrm{~cm}^{-1}$ is corresponding to the $\mathrm{C}-\mathrm{O}$ group of polysaccharides; only for the DOM from points 2 and 3 a signal is seen at $1384.6 \mathrm{~cm}^{-1}$ that corresponds to polyhydroxylated phenols. The spectroscopic profiles obtained for the DOM from the three sampling points agree largely with the FTIR spectrum of a humic acid, with the difference that the DOM does not present the signal at $2900 \mathrm{~cm}^{-1}$ corresponding to aliphatic C$\mathrm{H}$ stretching [38].

The fractionating of DOM by molecular weight was done using a $1 \mathrm{kDa}$ cutoff, because it was determined that the amount of organic carbon present in the fractions obtained with molecular weights greater than $30 \mathrm{kDa}$ was ten times smaller than that obtained using the $1 \mathrm{kDa}$ cutoff size. Table 2 shows the results of the determination of the organic carbon content in fractions F1 and F2. Upon carrying out the mass balance it is seen that part of the DOM is lost during the ultrafiltration process, which in general takes several days for its performance (120 continuous hours), so it is possible that DOM degradation processes as well as adsorption of it on the ultrafiltration membrane used may continue taking place [4]. The results showed that the predominant fraction in the DOM for the three sampling points is the one greater than $1 \mathrm{kDa}$, with a higher organic carbon content.

In relation to the FTIR of the F1 of the DOM (Supplementary Figure 3), a stronger signal is seen for sampling point 2 at $3500 \mathrm{~cm}^{-1}$ corresponding to a $\mathrm{H}$-bonded $\mathrm{OH}$ stretching of carboxyl, phenol, and alcohol; at $1630 \mathrm{~cm}^{-1}$ corresponding to $\mathrm{C}=\mathrm{O}$ stretching of $\mathrm{COO}^{-}$, ketonic $\mathrm{C}=\mathrm{O}$, and aromatic $\mathrm{C}=\mathrm{C}$ conjugated with $\mathrm{COO}^{-}$of pyridine to amino acid; at $1400 \mathrm{~cm}^{-1}$ corresponding to $-\mathrm{C}-\mathrm{H}$ of carbohydrates; and 
TABLE 2: Characterization of DOM fractions by UV-Vis spectroscopy and organic carbon content.

\begin{tabular}{|c|c|c|c|c|c|c|c|c|c|}
\hline \multirow{3}{*}{ Point } & \multicolumn{9}{|c|}{ Fraction } \\
\hline & \multicolumn{3}{|c|}{ Lower than $0.45 \mu \mathrm{m}$} & \multicolumn{3}{|c|}{ Greater than $1 \mathrm{kDa}(\mathrm{F} 1)$} & \multicolumn{3}{|c|}{ Lower than $1 \mathrm{kDa}(\mathrm{F} 2)$} \\
\hline & 1 & 2 & 3 & 1 & 2 & 3 & 1 & 2 & 3 \\
\hline$\overline{C_{\text {org }}\left(\mathrm{mg} \cdot \mathrm{L}^{-1}\right)^{\mathrm{a}}}$ & $2.4 \pm<0.1^{\mathrm{b}}$ & $2.9 \pm<0.1$ & $4.3 \pm 0.7$ & $0.90 \pm 0.30$ & $2.0 \pm 0.4$ & $2.4 \pm 0.5$ & $0.68 \pm 0.09$ & $1.5 \pm<0.1$ & $1.2 \pm 0.1$ \\
\hline SUVA & 2.19 & 3.41 & 6.97 & 5.09 & 5.46 & 2.14 & 10.7 & 10.2 & 12.9 \\
\hline$A 254 / A 436$ & 26.0 & 24.5 & 12.0 & 15.0 & 11.2 & 8.50 & 31.5 & 15.1 & 14.6 \\
\hline$A 254 / A 204$ & 0.117 & 0.119 & 0.116 & 0.170 & 0.251 & 0.111 & 0.034 & 0.228 & 0.128 \\
\hline$A 250 / A 365$ & 4.19 & 5.23 & 4.67 & 3.93 & 4.33 & 3.47 & 5.27 & 5.12 & 5.18 \\
\hline
\end{tabular}

${ }^{\mathrm{a}} \mathrm{C}_{\text {org }}$ : organic carbon content; ${ }^{\mathrm{b}}$ standard deviation.

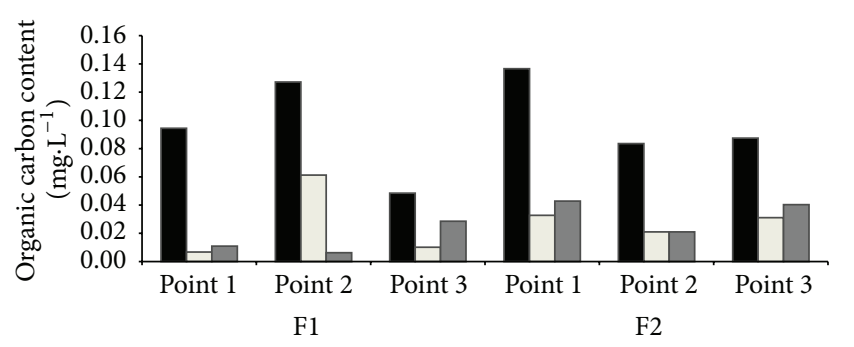

Hydrophobic base (F3)

$\square$ Hydrophobic acid (F4)

$\square$ Hydrophilic fraction (F5)

FIGURE 3: Organic carbon content of F1 and F2 fractionated by polarity.

at $1225 \mathrm{~cm}^{-1}$ corresponding to $\mathrm{C}-\mathrm{O}$ stretching and $\mathrm{O}-\mathrm{H}$ bending mainly of carboxyl groups. The signal at $1512 \mathrm{~cm}^{-1}$, corresponding to aromatic $\mathrm{C}=\mathrm{C}, \mathrm{N}-\mathrm{H}$ bending, and $\mathrm{C}=\mathrm{N}$ stretching, is seen only in fraction F1 from sampling point 1.

In relation to the FTIR of F2 (Supplementary Figure 4), it is noted that the signal at $2920 \mathrm{~cm}^{-1}$, corresponding to $\mathrm{OH}$ groups, is not seen, and the signals at 1630 and $1400 \mathrm{~cm}^{-1}$ are weaker. For fractions with the same molecular weight, a concordance is observed in the spectroscopic profile of the DOM from the three sampling points.

3.3. DOM Fractionation by Polarity. From the fractionation of the DOM by polarity two fractions were recognized: a hydrophilic fraction composed of simple organic acids, polyhydroxylated phenols, carbohydrates, amino acids, and amino sugars and a hydrophobic fraction that may contain phenols, hydrocarbons, fats, nucleic acids, and quinones.

The organic carbon content in the extracts fractionated by polarity (Figure 3) showed that the predominant fraction is hydrophobic, corresponding specifically to the hydrophobic base (F3), with a proportion of organic carbon between 55 and $84 \%$ with respect to the sum of the organic carbon of the three fractions, for each sampling point. The highest organic carbon content was that of F3 of the fraction smaller than $1 \mathrm{kDa}$ from point 1 , with a mainly natural origin, followed by F5 and finally F4.

When the organic carbon results of the different polarity fractions and the FTIR spectra of F1 and F2 are compared, it is seen that for F1 from point 2 the signals show a DOM with a highly hydrophobic character, because of the signal corresponding to hydrocarbons at $2930-2860$ and $1455 \mathrm{~cm}^{-1}$, in agreement with the higher organic carbon content present in $\mathrm{F} 3$ [22].

3.4. Analyzes of DOM and Its Fractions by UV-Vis. The SUVA parameter (Table 2), which allows describing the hydrophobic and hydrophilic character of the DOM obtained from natural water, was determined from the results of UV-Vis spectroscopy and the organic carbon content of each of the fractions. The results obtained for the DOM fraction were $2.19,3.41$, and 6.97 for points 1,2 , and 3, respectively, where a SUVA $>4$ indicates mainly hydrophobic and especially aromatic matter, while a SUVA $<3$ refers to mainly hydrophilic matter [32].

The results obtained for the extract fractionated by molecular weight showed that F2 has a strongly hydrophobic character for the three sampling points, but F1 does not, where a hydrophobic character is found only for sampling points 1 and 2 (Table 2).

The 254/436 absorbance ratios (Table 2) have been described in the range of 4.37 to 11.34 in the river water, associated with a terrestrial/allocthonous DOM that has a higher aromatic carbon content, associated with the presence of substances such as tannins and/or humic compounds derived from higher plants and organic matter from the soil $[39,40]$. The result obtained for the DOM from point 3 is within this range, but not so for points 1 and 2 , whose average value was 25 , indicating that the DOM is derived from a microbial source [41]. In relation to the extracts fractionated by molecular weight, $\mathrm{F} 2$ had higher A254/A436 ratios than F1 for the three sampling points.

The 254/204 and 250/365 absorbance ratios have been reported to be useful for the characterization of the DOM, whose A254/A204 ratio allows the correlation with the amount of aromatic carbon present in the DOM [42, 43], and the $A 250 / A 365$ ratio is used as an indicator of molecular size. The results show that the $A 254 / A 204$ values (Table 2) were similar for the DOM from the three sampling points, but not so for the different molecular weight fractions, where the ratio is greater in $\mathrm{F} 1$ and $\mathrm{F} 2$ from sampling point 2.

As to the $A 250 / A 365$ ratio (Table 2), the values obtained for the different molecular weight fractions coincide, pointing 


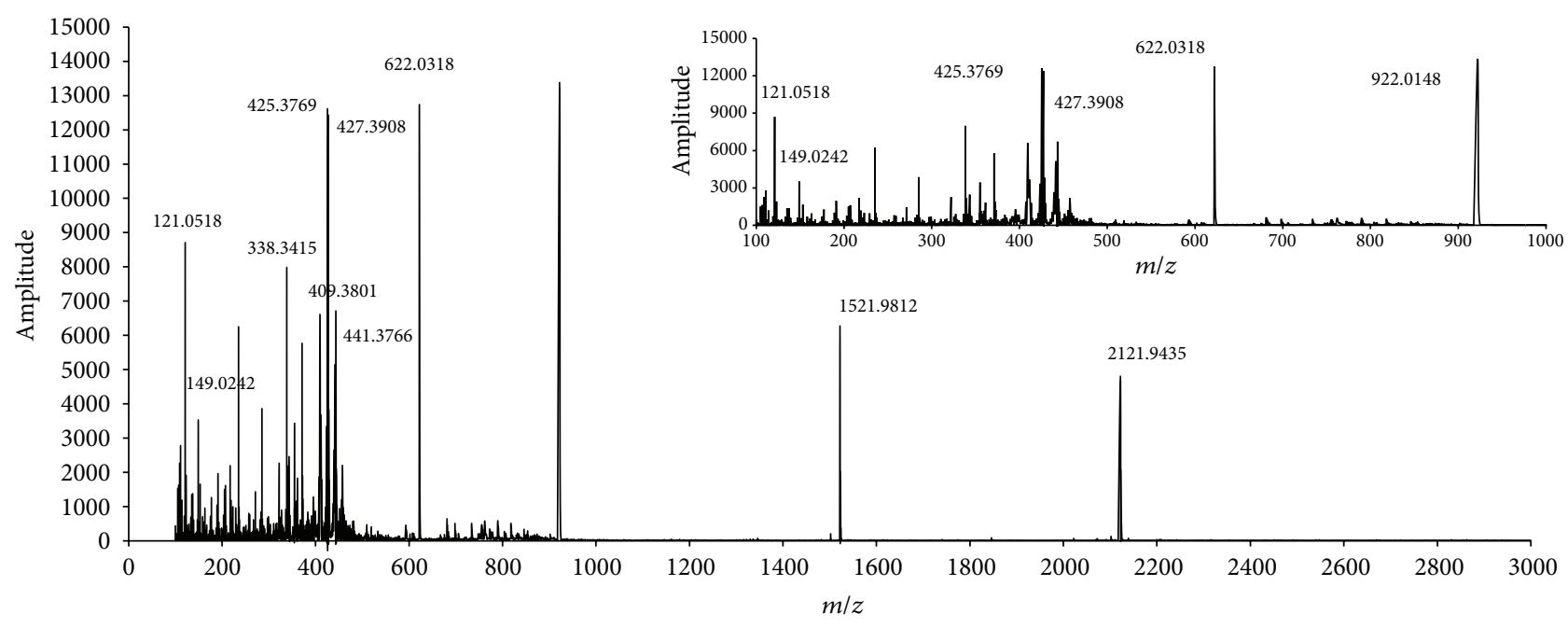

FIGURE 4: Mass spectrum of the DOM of size less than $0.45 \mu \mathrm{m}$ obtained from HA. Spectrum registered with DSA-TOF-MS.

TABLE 3: Residues of calibration at positive mode by DSA-TOF-MS.

\begin{tabular}{lc}
\hline Calculated mass & Residual \\
\hline 121.05087 & 0.00001 \\
322.04812 & -0.00021 \\
622.02896 & 0.00065 \\
922.00980 & -0.00034 \\
1251.97148 & -0.00038 \\
2121.93315 & 0.00027 \\
\hline
\end{tabular}

to the efficiency of the fractionating procedure with the ultrafiltration cell. The $A 250 / A 365$ results of the DOM indicate that the one from sampling point 1 has a lower molecular weight, followed by the DOM from sampling points 3 and 2 .

3.5. Analysis of the DOM and Its Fractions by DSA-TOFMS. The results of the DOM analysis by DSA-TOF- MS are presented in Figures 4 to 8 . The calibration results are presented in Table 3, where the residues obtained were lower than 0.0006 . The volume of calibrant solution used in the determinations was $20 \mu \mathrm{L}$ to increase the reproducibility of the results.

Studies have been conducted to characterize natural organic matter using electrospray ionization mass spectrometry; with this technique only the polar compounds are ionized, while purely aliphatic moiety in humic and fulvic acids is not detected, and Kujawinski et al. [23] have suggested that compounds with high carboxylic acid content may be susceptible to fragmentation during electrospray ionization.

The DSA is a type of ambient ionization source. Ambient mass spectrometry is classified by the ability to sample and ionize analytes directly from surfaces with little to no sample preparation.

The results of the standards of HA and LG, analyzed by DSA-TOF-MS, showed differences in the distribution of signals (Figures 4 and 5), which can be attributed to the higher number, size, and structural complexity of the masses of DOM obtained from HA.

In relation to the mass spectra obtained for the DOM of Bio-Bio River, the fragmentation pattern varies according to the origin of the DOM, where for sampling point 1 (Figure 6), of mainly natural origin, a spectrum similar to the pattern obtained for the masses of LG can be observed unlike the mass spectra of the sample points 2 and 3 (Figures 7 and 8), in which the distribution of the masses is more similar to that observed for the HA. This change in the DOM would reflect the greatest human activity that occurs in these sampling points. The importance of the humic fraction is because it has a high influence on the physicochemical characteristics of natural water systems because it increases the light attenuation and maintains the $\mathrm{pH}$ constant by the presence of organic acids that act as buffer and because it has the ability to form complexes with some elements, affecting the redox chemistry of trace metals [44].

A water system is a complex system, where the presence of organic matter can even modify some physicochemical properties such as electrical conductivity or $\mathrm{pH}$, but the content of organic matter does not necessarily correlate with the amount of DOM, since it will depend on the origin of organic matter. There is evidence that the concentration of dissolved organic carbon and $\mathrm{pH}$ are closely correlated with the molecular composition of the DOM in different types of aquatic systems. In this regard, Roth et al. [45] indicate that a higher $\mathrm{pH}$ of the molecular formulae of DOM had a lower degree of unsaturation and oxygenation, with a lower molecular size and greater abundance of nitrogen containing compounds. This may be because, at a higher $\mathrm{pH}$, a greater biological activity related to the greater abundance of nitrogen containing compounds; however at a lower $\mathrm{pH}$ there would be a greater abundance of tannins in the system, which can inhibit the biological breakdown of the DOM. 


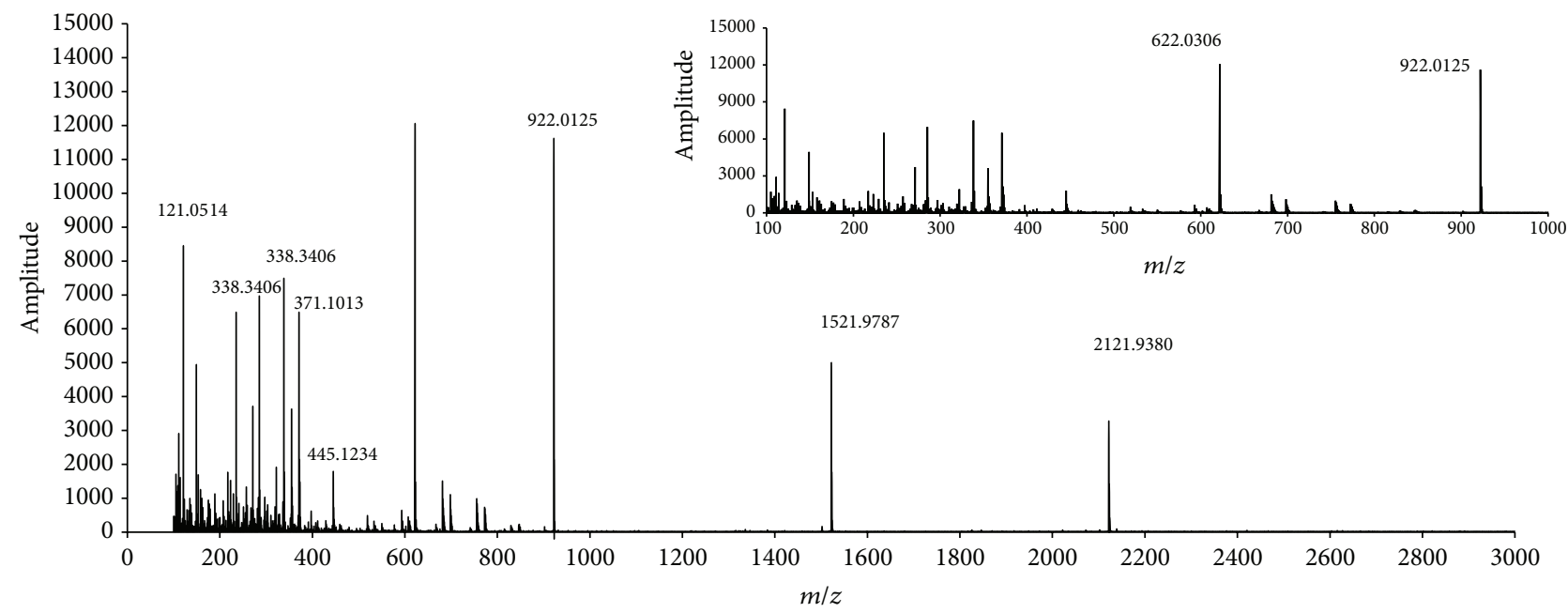

FIGURE 5: Mass spectrum of the DOM of size less than $0.45 \mu \mathrm{m}$ obtained from LG. Spectrum registered with DSA-TOF-MS.

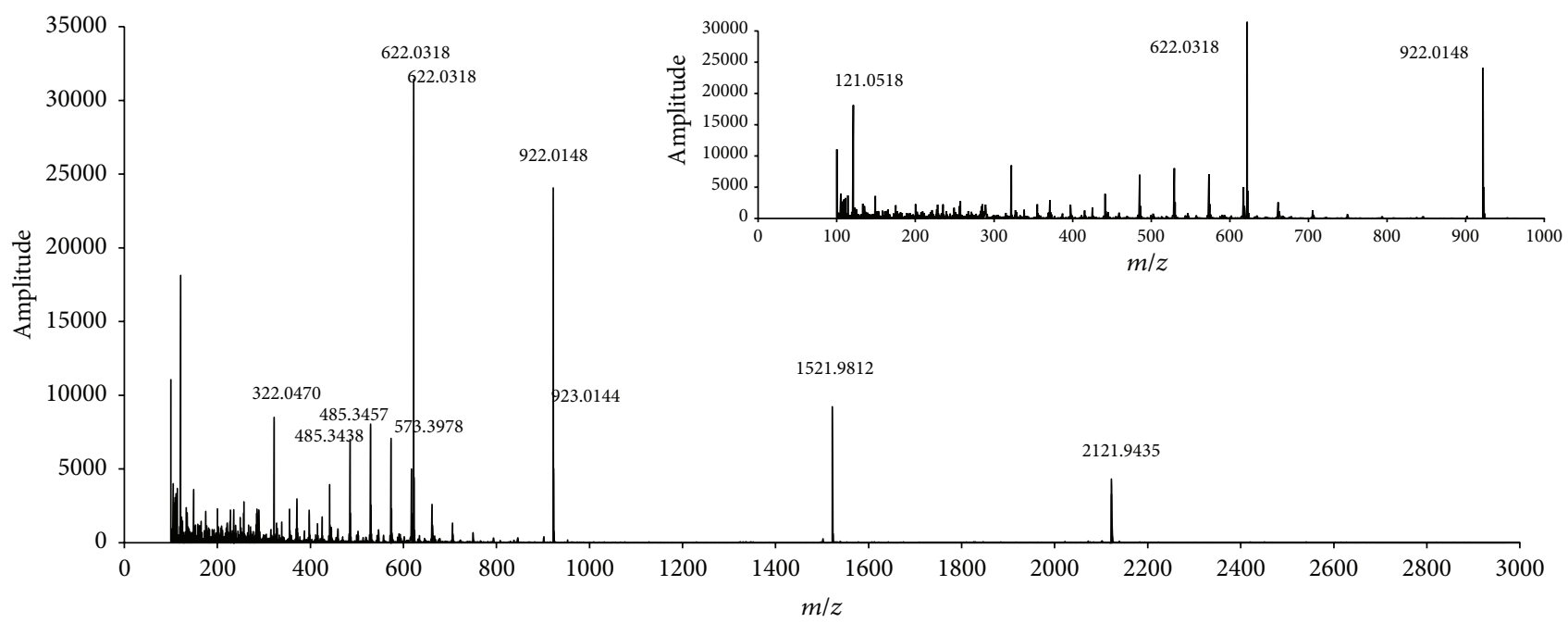

FIGURE 6: Mass spectrum of the DOM of size less than $0.45 \mu \mathrm{m}$ obtained from point 1 . Spectrum registered with DSA-TOF-MS.

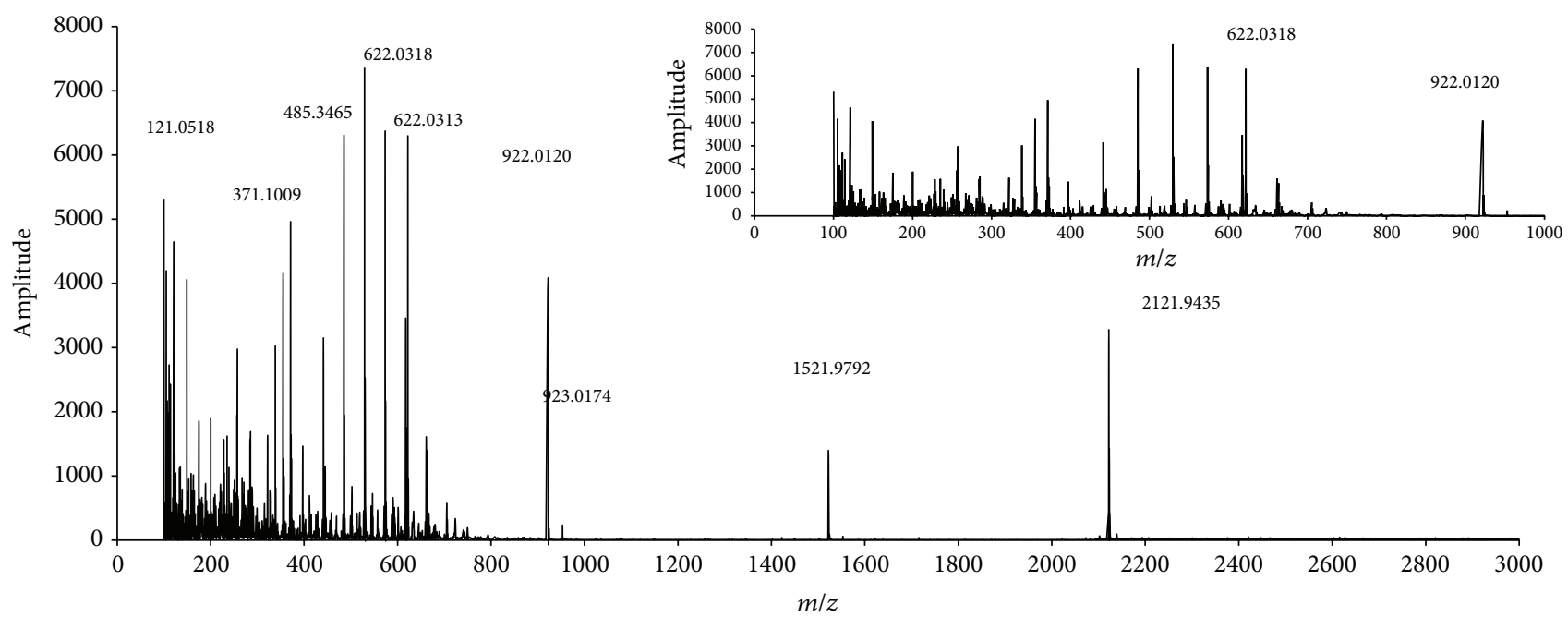

FIGURE 7: Mass spectrum of the DOM of size less than $0.45 \mu \mathrm{m}$ obtained from point 2 . Spectrum registered with DSA-TOF-MS. 


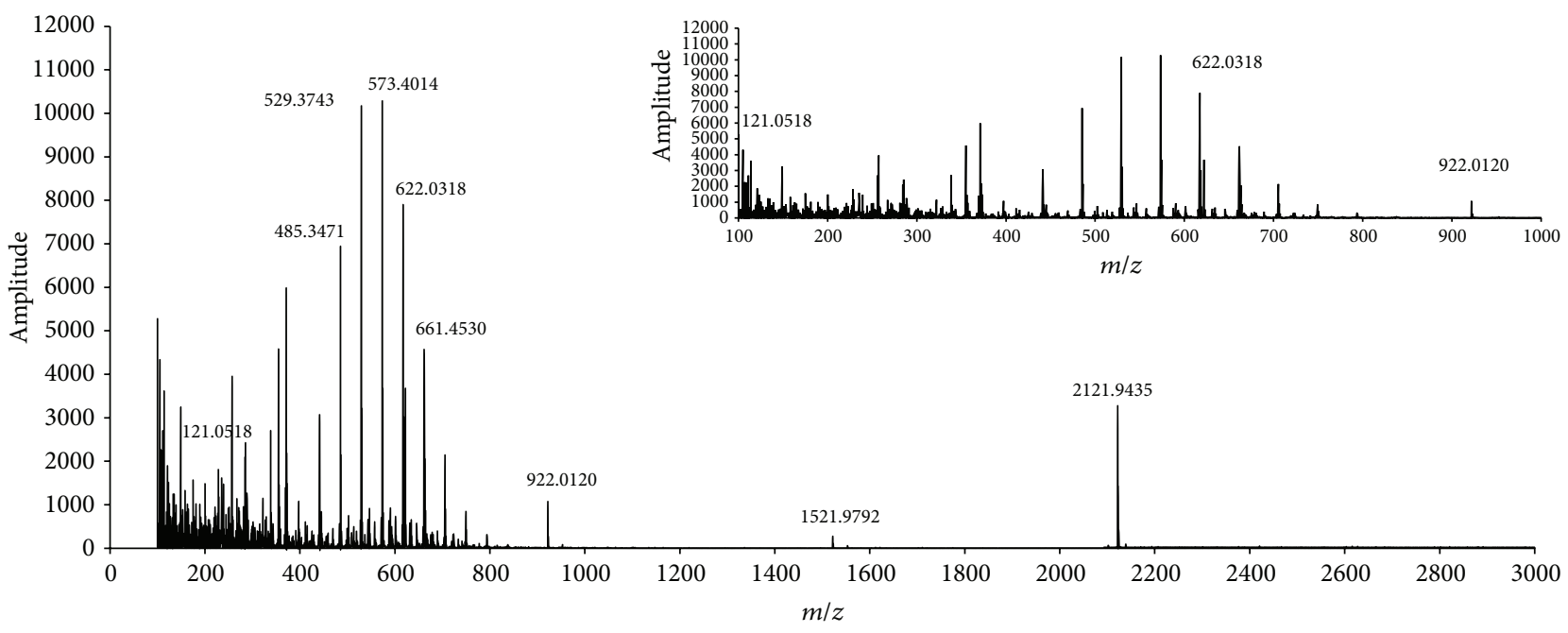

FIGURE 8: Mass spectrum of the DOM of size less than $0.45 \mu \mathrm{m}$ obtained from point 3. Spectrum registered with DSA-TOF-MS.

\section{Conclusions}

From the results it can be concluded that the DOM present in natural water is composed of macromolecules with a molecular weight range, chemical composition, and a specified spectroscopic profile that are similar for the three sampling points.

From the fractionation by molecular weight it was possible to determine for the three sampling points that the DOM has mainly a molecular weight greater than $1 \mathrm{kDa}$, with a hydrophobic character, where the molecular size is greater for point 2 , a sector with a high anthropic impact, followed by point 3 , and finally point 1 .

The effect of human activity is reflected in increased molecular size of the DOM, as well as increased organic carbon content and conductivity.

From the spectroscopic results it can be concluded that the DOM of the Rucalhue sector (point 1) has a terrestrial origin, with a high aromatic carbon content, distinguishing it from the DOM of the Laja and Concepción sectors (points 2 and 3), which have a greater anthropic impact.

The results of the DSA-TOF-MS show mass spectra of DOM points 2 and 3 of mainly anthropogenic origin were similar to that obtained for the deviation $\mathrm{AH}$, unlike that DOM of mainly natural origin of point 1 whose mass spectrum is consistent with that obtained for the standard LG. This shows that this technique offers advantages in structural characterization of DOM mainly because of its short time of analysis and ease of sample preparation.

\section{Competing Interests}

The authors declare that they have no competing interests.

\section{Acknowledgments}

This study was supported by National Fund for Scientific and Technological Development (Fondecyt), through the Project
Fondecyt no. 11110223 and the Project Fondequip no. EQM130119.

\section{References}

[1] J. A. Leenheer and J.-P. Croué, "Characterizing aquatic dissolved organic matter," Environmental Science and Technology, vol. 37, no. 1, pp. 18A-26A, 2003.

[2] K. Vancampenhout, K. Wouters, B. De Vos, P. Buurman, R. Swennen, and J. Deckers, "Differences in chemical composition of soil organic matter in natural ecosystems from different climatic regions-a pyrolysis-GC/MS study," Soil Biology and Biochemistry, vol. 41, no. 3, pp. 568-579, 2009.

[3] A. Nebbioso and A. Piccolo, "Molecular characterization of dissolved organic matter (DOM): a critical review," Analytical and Bioanalytical Chemistry, vol. 405, no. 1, pp. 109-124, 2013.

[4] A. Matilainen, E. T. Gjessing, T. Lahtinen, L. Hed, A. Bhatnagar, and M. Sillanpää, "An overview of the methods used in the characterisation of natural organic matter (NOM) in relation to drinking water treatment," Chemosphere, vol. 83, no. 11, pp. 1431-1442, 2011.

[5] S. H. Ruiz, S. Wickramasekara, L. Abrell, X. Gao, B. Chefetz, and J. Chorover, "Complexation of trace organic contaminants with fractionated dissolved organic matter: implications for mass spectrometric quantification," Chemosphere, vol. 91, no. 3, pp. 344-350, 2013.

[6] L. Li, Z. Zhao, W. Huang, P. Peng, G. Sheng, and J. Fu, "Characterization of humic acids fractionated by ultrafiltration," Organic Geochemistry, vol. 35, no. 9, pp. 1025-1037, 2004.

[7] B. Pan, B. Xing, W. Liu, G. Xing, and S. Tao, "Investigating interactions of phenanthrene with dissolved organic matter: limitations of Stern-Volmer plot," Chemosphere, vol. 69, no. 10, pp. 1555-1562, 2007.

[8] F. F. Sodré and M. T. Grassi, "Assessment of anthropogenic influences on copper complexation by aquatic dissolved organic matter using synchronous fluorescence," Journal of the Brazilian Chemical Society, vol. 18, no. 6, pp. 1136-1144, 2007.

[9] G. Zheng and W. S. Price, "Direct hydrodynamic radius measurement on dissolved organic matter in natural waters using 
diffusion NMR," Environmental Science and Technology, vol. 46, no. 3, pp. 1675-1680, 2012.

[10] Y. Chen, G.-P. Yang, G.-W. Wu, X.-C. Gao, and Q.-Y. Xia, "Concentration and characterization of dissolved organic matter in the surface microlayer and subsurface water of the Bohai Sea, China," Continental Shelf Research, vol. 52, pp. 97-107, 2013.

[11] N. Her, G. Amy, D. Foss, and J. Cho, "Variations of molecular weight estimation by HP-size exclusion chromatography with UVA versus online DOC detection," Environmental Science and Technology, vol. 36, no. 15, pp. 3393-3399, 2002.

[12] E. C. Ged and T. H. Boyer, "Molecular weight distribution of phosphorus fraction of aquatic dissolved organic matter," Chemosphere, vol. 91, no. 7, pp. 921-927, 2013.

[13] H.-C. Kim, M.-J. Yu, and I. Han, "Multi-method study of the characteristic chemical nature of aquatic humic substances isolated from the Han River, Korea," Applied Geochemistry, vol. 21, no. 7, pp. 1226-1239, 2006.

[14] A. S. Costa, E. D. A. Passos, C. A. B. Garcia, and J. D. P. H. Alves, "Characterization of dissolved organic matter in the Piauí river estuary, Northeast Brazil," Journal of the Brazilian Chemical Society, vol. 22, no. 11, pp. 2139-2147, 2011.

[15] H.-R. Schulten, "Interactions of dissolved organic matter with xenobiotic compounds: molecular modeling in water," Environmental Toxicology and Chemistry, vol. 18, no. 8, pp. 1643-1655, 1999.

[16] Q. Dong, P. Li, Q. Huang, A. A. Abdelhafez, and L. Chen, "Occurrence, polarity and bioavailability of dissolved organic matter in the Huangpu River, China," Journal of Environmental Sciences (China), vol. 26, no. 9, pp. 1843-1850, 2014.

[17] M. L. Wei-Haas, K. J. Hageman, and Y.-P. Chin, "Partitioning of polybrominated diphenyl ethers to dissolved organic matter isolated from arctic surface waters," Environmental Science and Technology, vol. 48, no. 9, pp. 4852-4859, 2014.

[18] G. Palma, A. Sánchez, Y. Olave, F. Encina, R. Palma, and R. Barra, "Pesticide levels in surface waters in an agriculturalforestry basin in Southern Chile," Chemosphere, vol. 57, no. 8, pp. 763-770, 2004.

[19] J. Narváez, P. Richter, and M. Inés Toral, "Preliminary physical chemical characterization of river waters and sediments affected by copper mining activity in central Chile. Application of multivariate analysis," Journal of the Chilean Chemical Society, vol. 52, no. 3, pp. 1261-1265, 2007.

[20] R. Barra, P. Popp, R. Quiroz, C. Bauer, H. Cid, and W. V. Tümpling, "Persistent toxic substances in soils and waters along an altitudinal gradient in the Laja River Basin, Central Southern Chile," Chemosphere, vol. 58, no. 7, pp. 905-915, 2005.

[21] R. Orrego, B. Jiménez, L. R. Bordajandi et al., "EROD induction and PCDD/F levels in fish liver from the Biobio River in Chile," Chemosphere, vol. 60, no. 7, pp. 829-835, 2005.

[22] J. A. Leenheer, "Comprehensive approach to preparative isolation and fractionation of dissolved organic carbon from natural waters and wastewaters," Environmental Science and Technology, vol. 15 , no. 5, pp. 578-587, 1981.

[23] E. B. Kujawinski, M. A. Freitas, X. Zang, P. G. Hatcher, K. B. Green-Church, and R. B. Jones, "The application of electrospray ionization mass spectrometry (ESI MS) to the structural characterization of natural organic matter," Organic Geochemistry, vol. 33, no. 3, pp. 171-180, 2002.

[24] E. M. Peña-Méndez, K. Novotná, D. Gajdošová, V. González, and J. Havel, "Characterization of humic substances of different origin by means of mass spectrometry and neural networks," Chemosphere, vol. 68, no. 11, pp. 2047-2053, 2007.
[25] D. Gajdošová, K. Novotná, P. Prošek, and J. Havel, “Separation and characterization of humic acids from Antarctica by capillary electrophoresis and matrix-assisted laser desorption ionization time-of-flight mass spectrometry: inclusion complexes of humic acids with cyclodextrins," Journal of Chromatography A, vol. 1014, no. 1-2, pp. 117-127, 2003.

[26] S. Daugherty and H. Crowe, "Automated direct sample analysis (DSA/TOF) for the rapid testing of drug compounds," 2013, http://www.perkinelmer.com/CMSResources/Images/44-152512APP_ 01_Illicit_Drugs.pdf.

[27] S. E. Hale, S. Endo, H. P. H. Arp, A. R. Zimmerman, and G. Cornelissen, "Sorption of the monoterpenes $\alpha$-pinene and limonene to carbonaceous geosorbents including biochar," Chemosphere, vol. 119, pp. 881-888, 2015.

[28] Y. Yang, B. Ligouis, C. Pies, C. Achten, and T. Hofmann, "Identification of carbonaceous geosorbents for PAHs by organic petrography in river floodplain soils," Chemosphere, vol. 71, no. 11, pp. 2158-2167, 2008.

[29] B. Ligouis, S. Kleineidam, H. Karapanagioti, R. Kiem, P. Grathwohl, and C. Niemz, "Organic petrology: a new tool to study contaminants in soils and sediments," in Environmental Chemistry, E. Lichtfouse, J. Schwarzbauer, and D. Robert, Eds., pp. 89-98, Springer, Berlin, Germany, 2005.

[30] H. Mash, P. K. Westerhoff, L. A. Baker, R. A. Nieman, and M.L. Nguyen, "Dissolved organic matter in Arizona reservoirs: assessment of carbonaceous sources," Organic Geochemistry, vol. 35, no. 7, pp. 831-843, 2004.

[31] ASTM, "Standard test method for filterable and nonfilterable matter in water," ASTM D5907-09, American Society for Testing and Materials (ASTM), 2014, https://www.astm.org/Standards/ D5907.htm.

[32] J. K. Edzwald and J. E. Tobiason, "Enhanced coagulation: US requirements and a broader view," Water Science and Technology, vol. 40, no. 9, pp. 63-70, 1999.

[33] A. M. Hansen, T. E. Kraus, B. A. Pellerin, J. A. Fleck, B. D. Downing, and B. A. Bergamaschi, "Optical properties of dissolved organic matter (DOM): effects of biological and photolytic degradation," Limnology and Oceanography, vol. 61, no. 3, pp. 1015-1032, 2016.

[34] R. G. Qualls and B. L. Haines, "Biodegradability of dissolved organic matter in forest throughfall, soil solution, and stream water," Soil Science Society of America Journal, vol. 56, no. 2, pp. 578-586, 1992.

[35] A. Charriau, L. Lesven, Y. Gao et al., "Trace metal behaviour in riverine sediments: role of organic matter and sulfides," Applied Geochemistry, vol. 26, no. 1, pp. 80-90, 2011.

[36] A. Kaschl, V. Römheld, and Y. Chen, "The influence of soluble organic matter from municipal solid waste compost on trace metal leaching in calcareous soils," Science of the Total Environment, vol. 291, no. 1-3, pp. 45-57, 2002.

[37] H. Ma, H. E. Allen, and Y. Yin, "Characterization of isolated fractions of dissolved organic matter from natural waters and a wastewater effluent," Water Research, vol. 35, no. 4, pp. 985996, 2001.

[38] H.-S. Shin, J. M. Monsallier, and G. R. Choppin, "Spectroscopic and chemical characterizations of molecular size fractionated humic acid," Talanta, vol. 50, no. 3, pp. 641-647, 1999.

[39] T. J. Battin, "Dissolved organic matter and its optical properties in a blackwater tributary of the upper Orinoco river, Venezuela," Organic Geochemistry, vol. 28, no. 9-10, pp. 561-569, 1998.

[40] T. Filep, E. Draskovits, J. Szabó, S. Koós, P. László, and Z. Szalai, "The dissolved organic matter as a potential soil quality 
indicator in arable soils of Hungary," Environmental Monitoring and Assessment, vol. 187, no. 7, pp. 479-490, 2015.

[41] R. Jaffé, J. N. Boyer, X. Lu et al., "Source characterization of dissolved organic matter in a subtropical mangrove-dominated estuary by fluorescence analysis," Marine Chemistry, vol. 84, no. 3-4, pp. 195-210, 2004.

[42] J. Hur, M. A. Williams, and M. A. Schlautman, "Evaluating spectroscopic and chromatographic techniques to resolve dissolved organic matter via end member mixing analysis," Chemosphere, vol. 63, no. 3, pp. 387-402, 2006.

[43] A. Assaad, S. Pontvianne, J.-P. Corriou, and M.-N. Pons, "Spectrophotometric characterization of dissolved organic matter in a rural watershed: the Madon River (N-E France)," Environmental Monitoring and Assessment, vol. 187, no. 4, p. 188, 2015.

[44] R. Jaffé, R. Mead, M. E. Hernandez, M. C. Peralba, and O. A. DiGuida, "Origin and transport of sedimentary organic matter in two sub-tropical estuaries: a comparative, biomarker-based study," Organic Geochemistry, vol. 32, no. 4, pp. 507-526, 2001.

[45] V.-N. Roth, T. Dittmar, R. Gaupp, and G. Gleixner, "The molecular composition of dissolved organic matter in forest soils as a function of $\mathrm{pH}$ and temperature," PLoS ONE, vol. 10, no. 3, Article ID e0119188, 2015. 

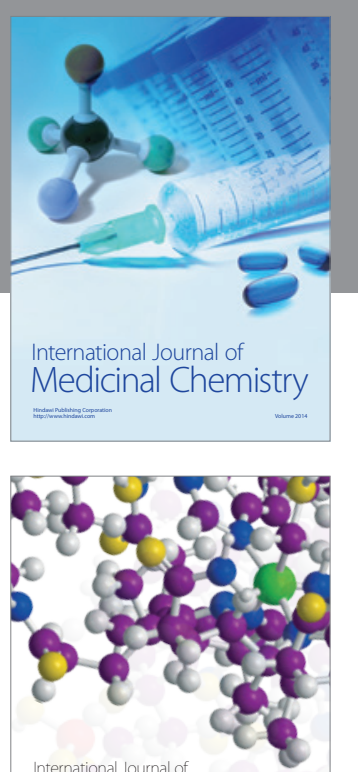

Carbohydrate Chemistry

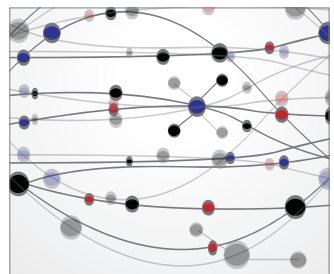

The Scientific World Journal
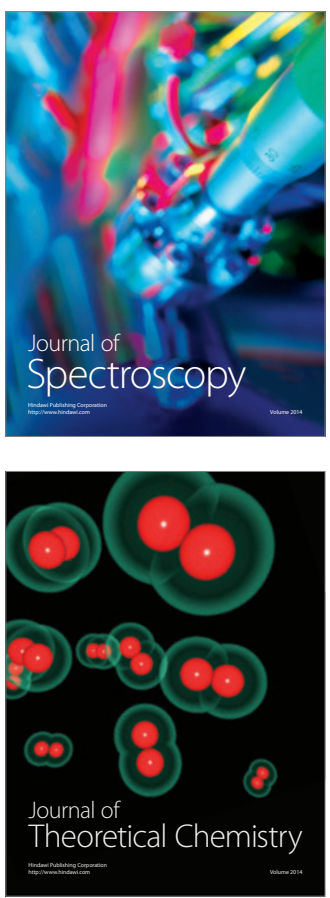
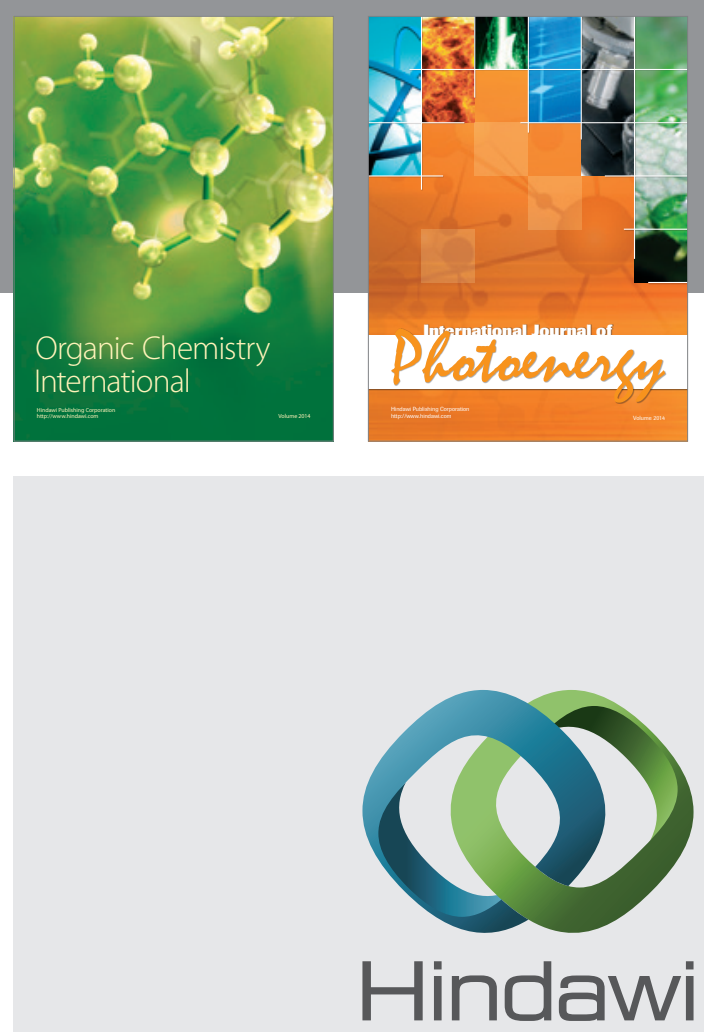

Submit your manuscripts at

http://www.hindawi.com

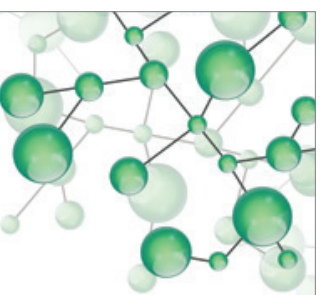

International Journal of

Inorganic Chemistry

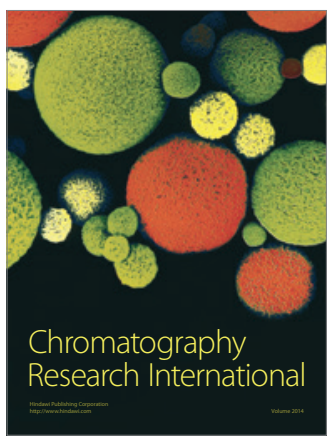

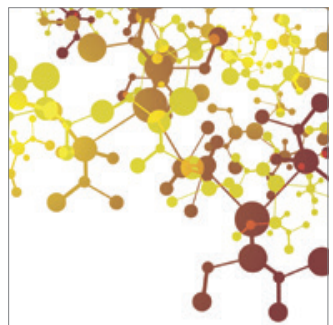

Applied Chemistry
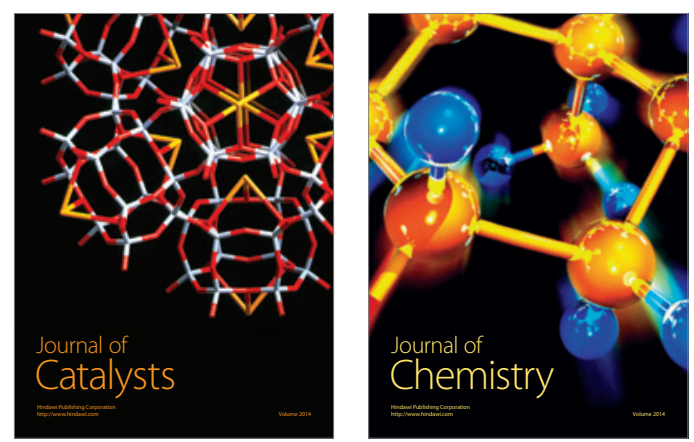
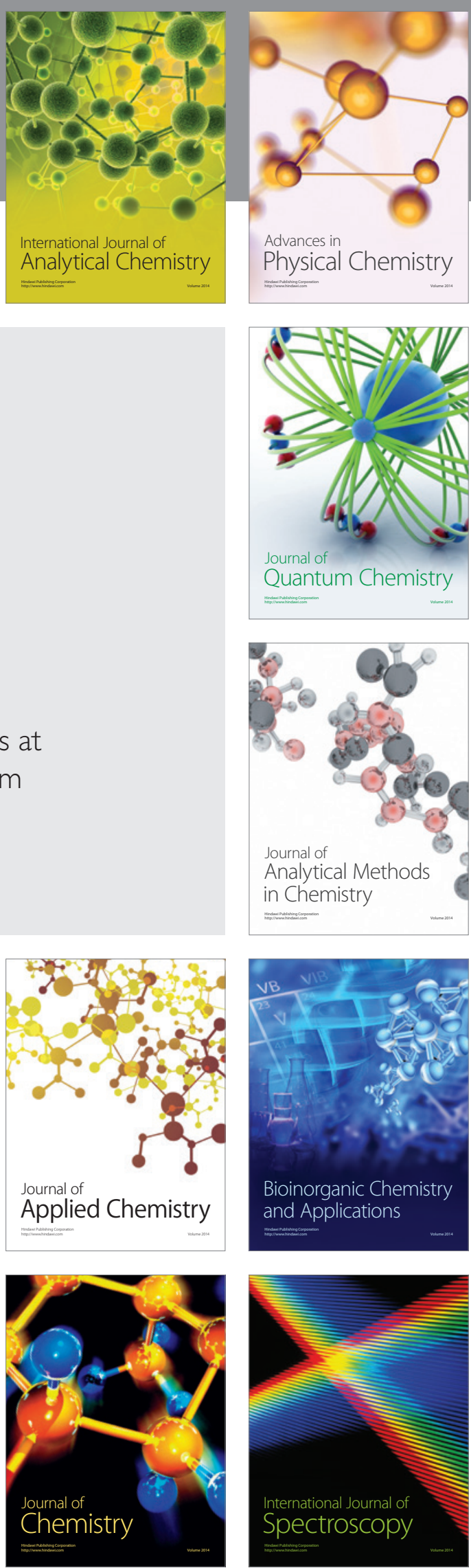